\title{
Exploring the diagnostic value of multilayer spiral computed tomography (MSCT) in thoracogastric airway fistula
}

\author{
Yue Zhao \\ Zhengzhou University First Affiliated Hospital \\ Yan-Wei Zeng \\ Zhengzhou University First Affiliated Hospital \\ Mei-Pan Yin \\ Zhengzhou University First Affiliated Hospital \\ Zhen Li \\ Zhengzhou University First Affiliated Hospital \\ Chun-Xia Li \\ Zhengzhou University First Affiliated Hospital \\ Yao-Zhen Ma \\ Zhengzhou University First Affiliated Hospital \\ Peng-Fei Xie \\ Zhengzhou University First Affiliated Hospital \\ Gang Wu ( $\sim$ wuganghenan2004@zzu.edu.cn) \\ Zhengzhou University First Affiliated Hospital
}

Research article

Keywords: Esophageal cancer, Stomach, Trachea, Fistula, Multilayer Spiral Computed Tomography

Posted Date: February 27th, 2020

DOI: https://doi.org/10.21203/rs.2.24773/v1

License: @ (i) This work is licensed under a Creative Commons Attribution 4.0 International License. Read Full License 


\section{Abstract}

Background

Thoracostomach-airway fistula is a rare complication of esophageal-cancer resection. We intended to explore the diagnostic value of multilayer spiral computed tomography (MSCT) in thoracostomach-airway fistula, to enhance its clinical understanding; evaluate an effective, convenient, and non-invasive diagnostic method; and provide the fundamentals for subsequent treatment.

Methods

The MSCT images and complete clinical data of 216 consecutive patients diagnosed with thoracogastric airway fistula were retrospectively analyzed.

Results

MSCT was able to determine the exact location, size of the fistula, and the adjacent bronchus between the fistula and bronchus in 192 out of 216 patients with thoracogastric airway fistula. All patients had pulmonary lesions including emphysema $(n=68)$, ground glass density $(n=25)$, bronchial wall thickening $(n=28)$, patchy high densities along the lung texture $(n=207)$, pulmonary consolidation $(n=104)$, atelectasis $(n=11)$, pulmonary nodules $(n=53)$, bronchiectasis $(n=19)$, lobular septal thickening $(n=5)$, cavity $(n=14)$, and pulmonary interstitial fibrosis $(n=6)$. Further, 95 cases showed pleural effusion, 184 showed pleural thickening, 4 had pneumothorax, and 2 had subcutaneous pneumothorax. 12 patients with thoracogastric airway fistula had anastomotic wall thickening (mean: $20.63 \pm 9.57$, range: $9.19-43.37 \mathrm{~mm}$ ), while 13 patients showed thoracic gastric wall thickening (mean: $22.83( \pm) 5.58 \mathrm{~mm}$, range: $12.32-31.24 \mathrm{~mm})$ on. 23 patients showed distant metastasis on MSCT.

Conclusions

MSCT can accurately display the location and size of thoracogastric airway fistula, as well as lung lesions, tumor recurrence, and distant metastasis, and provide the basis for the next therapy.

\section{Introduction}

Thoracogastric airway fistula (TGAF) is a rare complication of esophageal cancer resection with an incidence ranging between $0.3 \%$ and $1.9 \%$ [1, 2]. The literature on TGAF is rare, and most doctors lack a sufficient understanding of TGAF. TGAF has a very high mortality rate because it is often misdiagnosed as conditions including abnormal deglutition, esophageal tracheal fistula, and radiation pneumonitis, thereby preventing effective treatment [3, 4]. The internal diameter of the airway is relatively constant, and stent placement can effectively seal the fistula. As the location and diameter of the fistula vary, stents should be customized to achieve functional sealing of the fistula [5]. Hence, it is essential to determine the specific location of the air-filled track and measure the airway-related meridians to ensure appropriate stents selection.

As a non-invasive examination method, multilayer spiral computed tomography (MSCT) can not only directly display the fistula and classify TGAF through plain scan and 3D reconstruction but also measure the length of the trachea, bronchus, internal meridian, and fistula size. At the same time, MSCT can also provide more comprehensive information about lesions, such as the presence of pulmonary infection, atelectasis, tumor recurrence, and distant metastasis. It provides more reliable imaging data for clinical diagnosis and treatment [6]. Therefore, to explore the imaging characteristics and diagnostic value of MSCT in thoracic gastric airway fistula, we summarized the MSCT findings of TGAF.

\section{Materials And Methods}

\section{Patients}

The clinical data and MSCT imaging of 216 patients with TGAF who underwent chest computed topography (CT) in our hospital from January 2011 to April 2019 were retrospectively analyzed. The inclusion criteria were as follows: 1) All patients underwent anastomosis of esophagus, gastric arch, or neck after esophageal cancer resection. 2) The thoracic stomach was located in the original esophageal bed of the posterior mediastinum. 3) All patients had a confirmed diagnosis based on digestive tract radiography, bronchoscopy, or gastroscopy. 4) All patients underwent MSCT examination. This study had been carried out in accordance with the Code of Ethics of the World Medical Association and was approved by the First Affiliated Hospital of Zhengzhou University committee on human investigation. All methods were performed in accordance with the relevant guidelines and regulations. All patients provided signed informed consent.

\section{CT Scanning Methods}

GE Light speed 64-slice spiral CT scanner was used to perform the plain and enhanced scans (delay time: $30 \mathrm{~s}$ and $75 \mathrm{~s}$, respectively). The patient was placed in the supine position and scanned from the level of the hyoid bone to the lower edge of the liver. After deep inspiration, breath-hold scanning was performed. The CT scanning parameters were as follows: tube voltage, $120 \mathrm{kVp}$; tube current, $100 \mathrm{mAs}$; layer thickness, $5.0 \mathrm{~mm}$; layer spacing, $5.0 \mathrm{~mm}$; reconstruction layer thickness, $0.625 \mathrm{~mm}$; pitch, 1. A high-pressure syringe was used to inject iohexol ( $350 \mathrm{mg} \mathrm{l} / \mathrm{mL})$, a non-ionic contrast agent, through the anterior elbow vein, at a dose of $1.5 \mathrm{~mL} / \mathrm{kg}$ and a rate of $2.5-3.0 \mathrm{~mL} / \mathrm{s}$. The mediastinal window (window width: $350 \mathrm{HU}$, window position: $40 \mathrm{HU}$ ) and lung window (window width: $1000 \mathrm{HU}$, window position: $-700 \mathrm{HU}$ ) were obtained. 


\section{Image Post-processing And Interpretation}

The original image was transmitted to the workstation for multi-plane reconstruction ( $3.0 \mathrm{~mm}$ in thickness and $3.0 \mathrm{~mm}$ in spacing). The images of all patients were analyzed and interpreted by two experienced radiologists and recorded after arriving at a consensus. The CT findings included fistula location; fistula size (including mediastinal window and lung window); pulmonary condition (including pulmonary infection, atelectasis, pleural effusion, pericardial effusion, and pleura); thickening of the gastric wall; mediastinal lymph node; and distant metastasis. Among them, the thickest part of the lesion on the axial plane was chosen for measurement of the thickened wall.

\section{Results}

\section{Patient characteristics}

In this study, we included 216 patients (174 male and 42 female; mean age: $60.37 \pm 8.50$ years; age range: $31-84$ years) with TGAF.

\section{MSCT Presentations}

\section{Fistula}

Briefly, MSCT could directly visualize the exact location, size, and the relationship between the fistula and bronchus in 192 patients with TGAF (Table 1, Fig. 1). On axial view, 192 cases of fistula could be clearly displayed on the mediastinal window (mean: $8.20 \pm 5.03 \mathrm{~mm}$ and range: $1.43-25.92 \mathrm{~mm}$ ) and $185 \mathrm{cases}$ could be clearly displayed on the pulmonary window (mean: $7.23 \pm 5.65 \mathrm{~mm}$ and range: $0.64-43.9 \mathrm{~mm}$ On sagittal view, 185 cases of fistula were clearly displayed on the mediastinal window and 177 cases were clearly displayed on the pulmonary window. The mean fistula size on lung window was $8.14 \pm$ $6.29 \mathrm{~mm}$ (range: $0.64-43.49 \mathrm{~mm}$ ) and on mediastinal window was $9.82 \pm 6.64$ (range: $1.14-46.54 \mathrm{~mm}$ ). MSCT showed no fistula in 24 patients with TGAF.

Table 1

Characteristic of fistula in patients with thoracogastric airway fistula

\begin{tabular}{|c|c|c|c|c|c|c|c|}
\hline \multirow{2}{*}{$\begin{array}{l}\text { General characteristic } \\
\text { of fistula }\end{array}$} & \multicolumn{6}{|c|}{ positive manifestation } & \multirow[t]{2}{*}{ negative } \\
\hline & Trachea & Carina & $\begin{array}{l}\text { Right main } \\
\text { bronchus }\end{array}$ & $\begin{array}{l}\text { Left main } \\
\text { bronchus }\end{array}$ & $\begin{array}{l}\text { Right pulmonary } \\
\text { middle bronchus }\end{array}$ & $\begin{array}{l}\text { Left inferior lobe } \\
\text { bronchus }\end{array}$ & \\
\hline cases(n) & $76(35.2 \%)$ & $11(5.1 \%)$ & $36(16.6 \%)$ & $59(27.3 \%)$ & $9(4.2 \%)$ & $1(0.5 \%)$ & $24(11.1 \%)$ \\
\hline
\end{tabular}

\section{Pulmonary Lesions}

All 216 patients with TGAF had pulmonary lesions. Other recorded conditions were pulmonary emphysema $(n=68)$ including diffuse pulmonary emphysema $(n=23)$, ground glass densities $(n=25)$, bronchial wall thickening $(n=28)$, patchy high densities along the pulmonary texture $(n=207)$, pulmonary consolidation $(n=104)$, atelectasis $(n=11)$, pulmonary nodules $(n=53)$, bronchiectasis $(n=19)$, lobular septal thickening $(n=5)$, cavity $(n=14)$, and pulmonary interstitial fibrosis $(n=6)$ (Tables 2 and 3$)$.

Table 2

Pulmonary lesion manifestations in thoracogastric airway fistula

\begin{tabular}{|c|c|c|c|c|c|c|c|c|c|c|}
\hline $\begin{array}{l}\text { Pulmonary } \\
\text { lesion } \\
\text { manifestations }\end{array}$ & $\begin{array}{l}\text { Pulmonary } \\
\text { emphysema }\end{array}$ & $\begin{array}{l}\text { Ground } \\
\text { glass } \\
\text { densities }\end{array}$ & $\begin{array}{l}\text { Bronchial } \\
\text { wall } \\
\text { thickening }\end{array}$ & $\begin{array}{l}\text { Patchy } \\
\text { high } \\
\text { densities } \\
\text { along the } \\
\text { pulmonary } \\
\text { texture }\end{array}$ & $\begin{array}{l}\text { Pulmonary } \\
\text { consolidation }\end{array}$ & Atelectasis & $\begin{array}{l}\text { Pulmonary } \\
\text { nodules }\end{array}$ & Bronchiectasis & $\begin{array}{l}\text { Lobular } \\
\text { septal } \\
\text { thickening }\end{array}$ & $\begin{array}{l}\text { Pulr } \\
\text { inte } \\
\text { fibrr }\end{array}$ \\
\hline cases(n) & 68 & 25 & 28 & 207 & 104 & 11 & 53 & 19 & 5 & 6 \\
\hline
\end{tabular}


Table 3

Distribution of pulmonary lesion in thoracogastric airway fistula

\begin{tabular}{|c|c|c|c|c|c|}
\hline & $\begin{array}{l}\text { Right upper } \\
\text { lobe(n) }\end{array}$ & $\begin{array}{l}\text { Right middle lobe } \\
\text { (n) }\end{array}$ & $\begin{array}{l}\text { Lower lobe of right } \\
\text { lung(n) }\end{array}$ & $\begin{array}{l}\text { Left upper } \\
\text { lobe(n) }\end{array}$ & $\begin{array}{l}\text { Left lower } \\
\text { lobe(n) }\end{array}$ \\
\hline Emphysema & 34 & 4 & 2 & 5 & 2 \\
\hline Ground glass densities & 14 & 5 & 3 & 3 & 5 \\
\hline Bronchial wall thickening & 8 & 18 & 10 & 9 & 15 \\
\hline $\begin{array}{l}\text { Patchy high densities along the pulmonary } \\
\text { texture }\end{array}$ & 113 & 117 & 163 & 113 & 132 \\
\hline Pulmonary consolidation & 17 & 13 & 43 & 10 & 60 \\
\hline Atelectasis & 1 & 3 & 3 & 1 & 2 \\
\hline Pulmonary nodules & 27 & 23 & 25 & 22 & 25 \\
\hline Bronchiectasis & 6 & 3 & 6 & 4 & 6 \\
\hline Lobular septal thickening & 0 & 1 & 1 & 1 & 0 \\
\hline Pulmonary interstitial fibrosis & 1 & 1 & 2 & 1 & 1 \\
\hline Cavity & 7 & 0 & 5 & 2 & 1 \\
\hline
\end{tabular}

\section{Pleural Effusion, Pericardial Effusion, And Pleural Thickening}

Of the 216 patients with TGAFs, 95 had pleural effusion, of which 38 were bilateral effusions, 34 were right sided, and 23 were left sided. In addition, 184 patients had complications of pleural thickening (126 bilateral, 18 right sided, and 40 left sided); and four had pneumothorax (one had bilateral pleural thickening, three right pleural thickening, and two subcutaneous pneumothorax).

\section{Other Signs}

Twelve patients with TGAF had anastomotic stoma thickening (mean: $20.63 \pm 9.57 \mathrm{~mm}$, range: $9.19-43.37 \mathrm{~mm}$ ) and 13 patients had thoracic gastric wall thickening (mean: $22.83 \pm 5.58 \mathrm{~mm}$, range: $12.32-31.24 \mathrm{~mm}$ ).

MSCT revealed 23 cases of distant metastasis; as some patients presented with multiple metastases, there were 18 cases of lymph node metastasis, 8 cases of lung metastasis, 4 cases of liver metastasis and 2 cases of bone metastasis (Table 4).

Table 4

Other signs of thoracogastric airway fistula on MSCT

\begin{tabular}{|llllll|}
\hline \multicolumn{4}{|c|}{ Anastomotic wall and thoracic gastric wall thickening } & Metastasis & \\
\hline & $\begin{array}{l}\text { Anastomotic wall } \\
\text { thickening }\end{array}$ & $\begin{array}{l}\text { Thoracic gastric wall } \\
\text { thickening }\end{array}$ & $\begin{array}{l}\text { Lymph node } \\
\text { metastasis }\end{array}$ & $\begin{array}{l}\text { Lung } \\
\text { metastasis }\end{array}$ & $\begin{array}{l}\text { Liver } \\
\text { metastasis }\end{array}$ \\
\hline $\begin{array}{l}\text { Cases } \\
\text { (n) }\end{array}$ & 12 & 13 & 18 & 8 & 4 \\
metastasis
\end{tabular}

\section{Discussion}

Esophageal cancer is a common malignant tumor of the digestive tract. Surveys show that the annual global incidence of esophageal cancer is 455,800 , while the annual death toll is 400,200 [7, 8]. Esophageal resection remains the preferred treatment for resectable esophageal cancer [9]. Typically, extensive resection of esophageal cancer and intrathoracic anastomosis of the aortic arch or neck are performed to replace the esophagus with the stomach. The thoracic stomach runs on the original esophageal bed of the posterior mediastinum that is adjacent to the trachea, carina, and main bronchus. The TGAF is formed by abnormal communication between the thoracic stomach and the airway because of the poor anastomotic technique of the esophagus and stoma, infection in the anastomotic area, tumor recurrence, radiation-induced lesions, and ischemia. The mortality rate soared due because of repeated pulmonary infections and malnutrition [10].

Following esophagogastric anastomosis, patients experience remained gastric ulcer [11] due to bile reflux, gastric emptying disorder, ischemia, radiation therapy, and tumor recurrence. After gastric perforation, the perforation area communicates with the airway. Gastric juice is highly acidic and contains several digestive enzymes that spill through the fistula into the alkaline environment of the airway and lung, thereby resulting in chemical, corrosive, digestive pneumonia and secondary pulmonary infection. The patient may experience an irritating cough-like burning which is a typical characteristic of TGAF, because the symptom aggravates in a supine position and alleviates while being seated, in anteversion or semi-seated. We named this clinical manifestation as Burning-like Cough Syndrome in Recumbent Position. 
Traditional upper gastrointestinal radiography can locate the fistula; however, after oral administration of the contrast agent, it enters the airway through the fistula and aggravates the symptoms of cough and pulmonary infection, thereby limiting the presentation of atelectasis, inflammation, and pleural effusion. Compared with upper gastrointestinal radiography, MSCT is a common non-invasive imaging examination method that offers the advantages of being nonirritating and not aggravating pulmonary infection in addition to having a high spatial resolution. At the same time, MSCT can observe and analyze images in multi-window width, multi-window position, and multi-plane and can fully generalize the pathological changes [6].

In this study, MSCT could clearly display the fistula in 192 patients with TGAF and had a positive detection rate of $88.9 \%$. The negative results seen in 24 patients may likely be attributed to the small size of the fistula, circuitous course, or inflammation and edema at the fistula, but gastrointestinal radiography, bronchoscopy or gastroscopy verified the existence of the fistula. MSCT can display the location of the fistula and measure its size on multiple levels. It can also measure the length and diameter of the trachea and bronchus to provide effective reference data for the next treatment of airway-stent placement [12, 13]. Based on the location of the thoracogastric fistula and its communication with the airway as revealed by MSCT, we can divide TGAF into six types: $\mathbb{}$ TGAF: thoracogastric communicates with the trachea; $\otimes$ Thoracogastric carina fistula: thoracogastric fistula communicates with carina area (within $2 \mathrm{~cm}$ of carina and its upper part); $\nabla$ Thoracogastric left main bronchial fistula: thoracogastric fistula communicates with the left main bronchus; $₫$ Thoracogastric right main bronchial fistula: thoracogastric fistula communicates with the right main bronchus; $₫$ Thoracogastric right middle main bronchial fistula: thoracogastric fistula communicates with the right middle main bronchus; and $\otimes$ Thoracogastric bronchiole fistula: thoracogastric fistula communicates with the bronchioles on the left or right lung surface.

MSCT can distinctly show the pulmonary infection. However, the pulmonary infection in patients with TGAF varies and is not specific. However, $95.8 \%$ of the cases have patchy high-density shadows along the lung texture, which is distributed mostly in the lower lobe of the lung and is closely related to the location of the fistula. $48.1 \%$ of the cases suffered from pulmonary consolidation due to aggravated infection, which was characterized by a large high-density shadow of the lung lobe and air bronchogram in some lesions. Obstructive atelectasis may occur when viscous secretions or gastric contents block the trachea, bronchus, or trachea and bronchial wall owing to inflammatory stimulation and edema, resulting in narrowing or occlusion of the corresponding lumen, which is characterized by large dense shadows similar to the corresponding lobes. Pleural effusion was noted as a complication in $43.9 \%$ of the cases; pericardial effusion, in 43.5\%; and pleural hypertrophy, in $85.1 \%$. MSCT could also detect whether patients with TGAF had further complications of primary pulmonary diseases such as chronic bronchitis, emphysema, pulmonary interstitial fibrosis, and bronchiectasis [14].

MSCT can detect tumor recurrence and distant metastasis in patients with esophageal cancer after operation. In this study, 25 patients showed complications of anastomotic wall and chest gastric wall thickening, and contrast-enhanced scan of the same could be seen in varying degrees of enhancement. At such times, clinicians should suspect tumor recurrence. Twenty-three patients had distant metastasis. Therefore, MSCT can comprehensively elucidate the clinical changes in patients and provide more comprehensive information for optimum treatment.

In conclusion, if irritating cough occurs after esophagectomy with esophagogastric arch or cervical anastomosis, TGAF should be suspected and interpreted to improve the prognosis [15]. MSCT can provide direct visual confirmation of the fistula, and it can also find other lesion features providing reliable imaging data for clinical diagnosis and treatment.

\section{Declarations}

\section{Ethics approval and consent to participate}

This study had been was approved by the First Affiliated Hospital of Zhengzhou University committee on human investigation. All methods were performed in accordance with the relevant guidelines and regulations.

\section{Consent for publication}

Not applicable.

\section{Competing interests}

The authors declare that they have no competing interests.

\section{Availability of data and materials}

The datasets used and/or analysed during the current study are available from the corresponding author on reasonable request.

\section{Funding}

None.

\section{Authors' contributions}

Gang Wu designed and revised the work; Yue Zhao, Yan-Wei Zeng, Mei-Pan Yin drafted and interpreted the work; Yao-Zhen Ma, Zhen Li, Chun-Xia Li and PengFei Xie analysed the data. All authors read and approved the final manuscript.

\section{Acknowledgements}

None. 


\section{References}

1. Okuyama M, Saito R, Motoyama S, et al. Histological confirmation of healing of gastrobronchial fistula using a muscle flap. Ann of Thorac Surg. 2002;73:1298-1299. 2. Shi H, Wang WP, Gao Q, et al. Single-stage surgical repair of airway gastric fistula after esophagectomy. J Cardiothorac Surg. 2014;9:30. 3. Reed MF, Mathisen DJ. Tracheoesophageal fistula. Chest Surg Clin N Am. 2003;13:271-289. 4. Wang F, Yu H, Zhu MH, et al. Gastrotracheal fistula: treatment with a covered self-expanding Y-shaped metallic stent. World J Gastroenterol. 2015;21:1032-1035. 5. Han X, Yin M, Li L, et al. Customized airway stenting for bronchopleural fistula after pulmonary resection by interventional technique: single-center study of 148 consecutive patients. Surg Endoscopy. 2018;32:4116-4124. 6. Sun JS, Park KJ, Choi JH, et al. Benign bronchogastric fistula as a late complication after transhiatal oesophagogastrectomy: evaluation with multidetector row CT. The British journal of radiology. 2008;81:255-8. 7. Torre LA, Bray F, Siegel RL, et al. Global cancer statistics, 2012. CA: a cancer journal for clinicians. 2015;65:87-108. 8. Zeng H, Chen W, Zheng R, et al. Changing cancer survival in China during 200315: a pooled analysis of 17 population-based cancer registries. The Lancet Global health. 2018;6:e555-e67. 9. Aguilo Espases R, Lozano R, Navarro AC, et al. Gastrobronchial fistula and anastomotic esophagogastric stenosis after esophagectomy for esophageal carcinoma. The Journal of thoracic and cardiovascular surgery. 2004;127:296-7. 10. Bennie MJ, Sabharwal T, Dussek J, et al. Bronchogastric fistula successfully treated with the insertion of a covered bronchial stent. European radiology. 2003;13:2222-5. 11. McDermott M, Hourihane DO. Fatal non-malignant ulceration in the gastric tube after oesophagectomy. Journal of clinical pathology. 1993;46:483-5. 12. Li YD, Li MH, Han XW, et al. Gastrotracheal and gastrobronchial fistulas: management with covered expandable metallic stents. Journal of vascular and interventional radiology : JVIR. 2006;17:1649-56. 13. Xin-Wei Han, Gang Wu, Ming Zhao, et al. Clinical manifestations and computed tomography diagnosis for thoracostomach airway fistula『Shijie Huaren Xiaohua Zazhi 2007;15:905-908囚 14. Scheeren B, Gomes E, Alves G, et al. Chest CT findings in patients with dysphagia and aspiration: a systematic review. Jornal brasileiro de pneumologia : publicacao oficial da Sociedade Brasileira de Pneumologia e Tisilogia. 2017;43:313-8. 15. Jha PK, Deiraniya AK, Keeling-Roberts CS, et al. Gastrobronchial fistula-a recent series. Interactive cardiovascular and thoracic surgery. 2003;2:6-8.

\section{Figures}

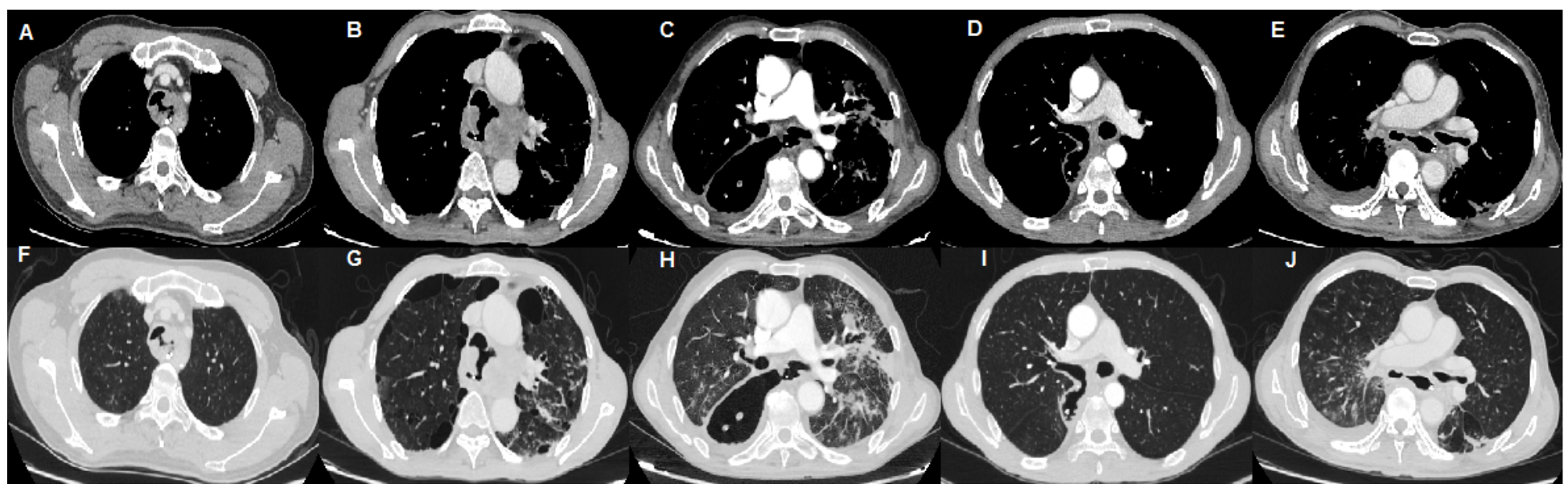

Figure 1

MSCT showing the different types of TGAF. Thoracogastric tracheal fistula (A, F), Thoracogastric carina fistula (B, G), Thoracogastric left main bronchial fistula $(C, H)$, Thoracogastric right main bronchial fistula (D, I), Thoracogastric right middle bronchial fistula (E, J). 